\title{
CURSOS E PERCURSOS, CALÇOS E PERCALÇOS DE FORMADORES DE DOUTORES EM EDUCAÇÃO EM CIÊNCIAS E EDUCAÇÃO MATEMÁTIÇA
}

\author{
COURSES AND DISTANCES, WEDGES AND DIFFICULTIES \\ OF DOCTORS' FORMERS IN \\ SCIENCE AND MATHEMATICS EDUCATION
}

Profa. Dra. Rosália M. R. de Aragão ${ }^{1}$

\section{RESUMO}

A investigação-narrativa, como vertente da pesquisa qualitativa, que ora apresentamos, é concernente ao Programa de Doutorado na Área de Educação em Ciências e Matemática, o qual se constituiu no âmbito de uma Associação em Rede de Instituições do Ensino Superior - Universidades e Institutos Federais - como IES situadas na Amazônia Legal, cujas responsabilidades e atribuições são compartilhadas em sua realização. A problemática posta sob enfoque advém da necessidade de cultivo doutoral das ações, reações e atitudes de doutores já em exercício em outras áreas e que resolvem migrar para a Área de Educação em Ciências e de Educação Matemática para assumir - em colaboração - a formação de Doutores em Educação em Ciências ou em Educação Matemática tal como expressa a proposição do Doutorado em REDE. Nessa perspectiva, doutores profissionalmente vinculados a IES da Amazônia Legal ${ }^{2}$ assumem parcerias tendo em vista a ampliação do número de professores titulados para atuarem na formação de doutores na REDE recém criada - mesmo já sendo doutores e atuando nas ditas "áreas duras" ou em áreas afins. Buscam, então, credenciar-se no recém criado Programa de Doutorado, com desejo e disponibilidade de migrar, como dissemos, para a Ârea enfocada e avançar partilhando efetivamente da formação científicopedagógica específica - e de qualidade positiva diferenciada para melhor - de novos doutores em Educação em Ciências e Educação Matemática. Os "doutores migrantes" visam estabelecer-se neste novo/outro Programa assumindo novas relações formativas de modo a propiciar tanto a visibilidade necessária para esta Área na sua Região de inserção, quanto a produção de respostas positivas e desejáveis para o avanço acadêmico, científico e pedagógico do Ensino Superior na formação de doutores. Esses doutores-formadores do presente, credenciados há dois anos no Programa em REDE em desenvolvimento, passam a ser investigados - nos termos da modalidade investigativa-narrativa da pesquisa qualitativa, à luz de fundamentos epistemológicos, teóricos e metodológicos da docência e da pesquisa em seus processos de adesão e de resistência ao que é proposto -, especialmente em relação a (i) participação como docentes-pesquisadores titulados formando doutores de qualidade para este século e gerando produção acadêmica nas Áreas enfocadas pela REDE, bem como a (ii)

\footnotetext{
${ }^{1}$ Professora e Pesquisadora da Universidade do CEUMA - UNICEUMA, e Professora Colaboradora da Universidade Federal do Pará - UFPA. rosalia.aragao@uol.com.br

${ }^{2}$ Referimo-nos a NOVE ESTADOS DA REGIÃO NORTE, quais sejam, os Estados do Acre, do Amapá, do Amazonas, do Maranhão, do Mato Grosso, do Pará, de Rondônia, de Roraima e do Tocantins, bem como a 25 Instituições de Ensino Superior associadas em REDE que se situam na referida Amazônia Legal.
} 
evidências de interesse e comprometimento - como Doutores em exercício na formação de novos doutores - quer com a qualidade do Ensino Superior no qual atuam, quer com a melhoria de qualidade do Ensino Básico, e da Pesquisa Científica na Região em que se situa esta REDE. Os resultados desta investigação desde que não se expressem alvissareiros em relação à qualidade dos novos doutores que se quer diferenciados, certamente, implicam esforços adicionais para atingir o que se põe como desiderato de muitos dos professoresdoutores e pesquisadores, sobretudo, pelas próprias condições, de migrantes de outras para a Área de Educação em Ciências e de Educação Matemática. As proposições e ações daí advindas impõem conhecer e conscientizar-se das questões epistemológicas e teóricometodológicas desta sua nova/outra área de atuação profissional. Isto se torna, sobretudo, relevante para que possam superar tradicionais pressupostos de uma formação doutoral positivista, externalista e fragmentária, largamente presente nesses termos no processo de formação docente do século passado (XX), mas, cujo cultivo neste século (XXI) se torna imprescindível descartar para abolir a visão dualista e hierárquica entre saberes e práticas docentes, substituindo-a por outra visão posta numa perspectiva político-epistemológica que enseje explicitar que nenhuma sociedade é capaz de pensar a si mesma sem a "religação" dos saberes e práticas de suas instituições educacionais.

PAlAVRAS-CHAVE: Formação de Doutores - Competência científica - Competência pedagógica - Questões epistemológicas - Cultivo Doutoral

\section{ABSTRACT}

The problem put under focus stems from cultivation of doctoral actions, reactions and attitudes of doctors already practising in other areas and that resolve to migrate to the areas of Science and Math Education to take-on collaboration-training for new doctors formation in Science Education or Mathematics Education, in accord with North Regional Brazilian context claims. With this in mind, doctors professionally bound to higher education Institutions - Universities and Federal Institutes - as a NET located in Legal Amazon assume responsibilities which include taking on partnerships in order to increase the number of teachers held for the training of doctors in the newly created NET. Even already being doctors and working in the so-called "hard areas" or in related fields, these doctors seek accreditation in a newly created doctoral program, with desire and willingness to migrate to focus and share scientific-pedagogical training in a high positive quality new doctors in Education Science and Mathematics Education. The "migrant doctors" aim to establish themselves in this new/other program assuming new formative relationships in order to provide both the necessary visibility to this area in its region of insertion, and the production of positive and desirable responses for the academic, scientific and pedagogical advancement of higher education in the training of doctors. These doctors who are working in the NET for accrediting doctor trainers since two years in a developing regional programme will be investigated pursuant to investigative narrative mode of qualitative research, in the light of epistemological, theoretical and methodological foundations of teaching and research. So as, in their accession processes or proposed-resistance the migrating doctors will be investigated especially in relation to both (i) their participation as teachers-researchers held forming quality doctors for this century while generating academic production in the areas being focused on by the NET, and (ii) evidence of interest and commitment as doctors in exercise in the training of new doctors aiming both with the quality of higher education in which they act, and with the improvement of the quality of basic education, and scientific research in the 
North Region in which this NET works in Brazilian context. The results of this investigation other than to express joy in relation to the quality of the new doctors to be differentiated, certainly imply further efforts of the professors-doctors and researchers in particular, by the conditions of other migrants to the area of Science and Mathematics Education. The propositions and actions thus arising require knowing and awareness of theoreticalmethodological and epistemological issues for this new professional area of expertise. This becomes especially relevant in order to overcome traditional assumptions of a positivist and fragmentary doctoral training position, largely present in these terms in the teacher training process of the last century (XX), but whose cultivation in this century (XXI) becomes essential to discard to abolish the two-tier and hierarchical vision between knowledge and teaching practices, replacing it with another vision put in a political and epistemological perspective.

Keywords: Doctors scientific and pedagogical competence - Epistemological and pedagogical issues - Doctoral actions cultivation

Two roads diverged in a Wood and I...

...I took the less travelled by...

And that has made all the difference.

Robert Frost

\section{A RAZÃO JÁ NÃO PODE ADORMECER NA TRADIÇÃO ${ }^{3}$}

O Programa de Pós-graduação Stricto Sensu, em nível de Doutorado, ora sob enfoque, foi elaborado no contexto do 'Projeto Acelera Amazônia'. Este Programa acadêmico está constituído como "curso novo de Doutorado em Educação em Ciências e Matemática”, em função de uma Associação em Rede de Instituições de Ensino Superior da Região Amazônica Brasileira, em sua feição legal ${ }^{4}$. Neste âmbito, o Programa abrange os Estados do Acre, Amapá, Amazonas, Maranhão, Mato Grosso, Pará, Rondônia, Roraima e Tocantins, bem como as suas 25 Instituições de Ensino Superior.

As ações acadêmicas que vêm se projetando neste Programa de Doutorado em REDE se inserem na Área de Ensino de Ciências e Matemática da CAPES, e situam-se no Comitê de Avaliação de Programas de Ensino. Tem como meta formar 100 doutores até 2016 na Amazônia Legal, bem como constituir programas de pós-graduação stricto sensu em várias

\footnotetext{
${ }^{3}$ Parafraseando Gaston Bachelard.

${ }^{4}$ Esta Associação foi instituída e estruturada a partir do Fórum de Pró-reitores de Pós-Graduação da Região Norte, na perspectiva da implantação institucional conjunta para constituir a REDE AMAZÔNICA DE EDUCAÇÃO EM CIÊNCIAS E MATEMÁTICA - REAMEC.
} 
Universidades, por meio de ações acadêmicas colaborativas entre as IES e os doutores existentes na Região, na Área nominada e em áreas afins. Para tanto, vem contando com a participação de cerca de sete pesquisadores-doutores de outras universidades das Regiões Sudeste-Sul na formação doutoral de qualidade de novos professores-pesquisadores para atuarem nesta Área, bem como de cerca 15 doutores com formação e experiência na área, uma dezena de professores-pesquisadores, doutores iniciantes na Área enfocada ${ }^{5}$, nos Polos Acadêmicos definidos, bem como cerca de trinta (30) recém doutores que ainda não atendem a condições burocráticas de orientação na Área.

\section{NÃO MAIS CONTAR COM A MEMÓRIA PARA RECITAR TAUTOLOGIAS ${ }^{6}$}

O Programa de Pós-Graduação em Educação em Ciências e Matemática - Doutorado -, autorizado pela $\mathrm{CAPES}^{7}$, foi instalado na Universidade de Mato Grosso - UFMT -, considerada sede da REDE como instituição propositora e responsável pela Coordenação Geral das Ações Acadêmicas de formação doutoral.

Tal REDE para ser implantada com perspectiva de sucesso das ações conjuntas tendo em vista a obtenção de competência específica de novos doutores, na Região, encontra-se organizada em TRÊS POLOS ACADÊMICOS, de acordo com o Projeto apresentado à CAPES, a saber:

1)Polo Acadêmico UFMT (Mato Grosso);

2) Polo Acadêmico UFPA (Pará) e

3) Polo Acadêmico UEA (Amazonas).

Tais Polos Acadêmicos são previstos para desenvolver ações conjuntas e articuladas, de acordo com o plano curricular elaborado e aprovado pela CAPES, tendo em vista a efetiva formação de doutores diferenciados positivamente em qualidade para implantarem, em futuro próximo, outros programas de Mestrado e Doutorado. Sendo assim, por suposto, novos programas decorrentes devem primar por idêntico nível de qualidade obtida e considerada desejável para este Programa que está sendo propiciado pela REDE em sua primeira versão.

$\mathrm{Na}$ esteira dessas ideias, a Associação em REDE organiza-se por meio de convênios diretamente firmados com cada uma das vinte e cinco IES da Amazônia Legal. Em termos de realização específica, tais instituições organizam-se em IES Polo - Coordenadoras Estaduais e outras IES Colaboradoras. Cada IES Coordenadora Estadual representa as IES participantes da REDE no respectivo Estado, e coordena as ações que visam assegurar a gestão administrativa e acadêmica do Programa da Rede neste Estado. A IES Coordenadora Estadual $^{8}$ articula-se com as demais IES Colaboradoras do Estado, por meio de protocolos de integração, convênios, termos de cooperação, ou de outras formas legais que oficializem

\footnotetext{
${ }^{5}$ Referimo-nos a professores doutores cuja experiência doutoral diferenciada do âmbito de disciplinas e seminários se restringe à orientação de duas ou três dissertações de mestrado e a pesquisa de doutorado na qual se envolveram até então que lhes credencia à orientação de doutorado disse respeito à de sua própria tese. Embora esta seja uma situação usual de recém doutores, o que nos parece pouco usual é a ausência de interação acadêmica para intensificar a dinâmica de relação com os pares, bem como a falta de estudos concernentes à nova área de atuação de forma tal que possa vir a assegurar novas experiências e avanços na qualidade e versatilidade da conduta doutoral.

${ }^{6}$ Parafraseando Gaston Bachelard.

7 - Foi autorizado pela CAPES no primeiro semestre de 2010 e instalado, em novembro de 2010, na Universidade de Mato Grosso - UFMT -, considerada sede da REAMEC como instituição propositora e responsável pela Coordenação Geral das Ações Acadêmicas de formação doutoral.
}

${ }^{8}$ No caso do Estado do Maranhão, a coordenação estadual vem sendo assumida pela UNIVERSIDADE DO CEUMA UNICEUMA, como integrante da REDE. 
parcerias instituídas. Os doutores representantes dessas Coordenações Estaduais, bem como das IES Colaboradoras compõem o Colegiado do Programa de Doutorado proposto e mantido pela Associação de IES. Dentre as coordenações participantes do Colegiado são escolhidas, para a administração do Programa, a Coordenação e a Vice-coordenação Geral da REDE' ${ }^{9}$, bem como as Coordenações de Polo, estas por indicação da respectiva Instituição Polo.

As IES Associadas e Colaboradoras - vinculadas à REDE proposta - mantêm cursos de Graduação, de Pós-Graduação Lato Sensu, bem como alguns em nível de Stricto Sensu na área de inserção do Doutorado em pauta, e em áreas afins. Na Área de Educação/Ensino de Ciências e Matemática são 146 cursos de Licenciatura, mais de uma centena de cursos de Especialização e cerca de meia dúzia de Programas de Mestrado e um de Doutorado.

O Polo Acadêmico UFMT, situado em Cuiabá, contava, à época da elaboração da proposta, com um grupo de docentes doutores em Educação em Ciências e Matemática que sustentavam uma linha de pesquisa nessa área, no Programa de Mestrado em Educação da Instituição. Essa experiência com a formação de mestres na área do Programa em Rede habilitou a equipe a assumir, além da coordenação geral, o respectivo polo acadêmico, formado por doutores e doutorandos dos Estados do Mato Grosso, Tocantins e Rondônia. Assim, congregam-se nesse polo acadêmico, as seguintes IES: UFMT, UNEMAT, IFMT (MT); UNIR e IFRO (RO). No momento, nenhuma IES do Estado do Tocantins encontra-se associada à REDE.

O Polo Acadêmico UFPA, situado em Belém do Pará, por manter desde 2002 Programa de Mestrado Acadêmico em Educação em Ciências e Matemáticas - Mestrado e Doutorado, desde 2009, - assume a responsabilidade de congregar docentes doutores do Estado do Maranhão, credenciados no Programa e na CAPES - provenientes da UEMA, da UFMA, do IFMA, da UEPA, do IFPA, da UNAMA, da UNIFAP, do IFAP, da UNICEUMA e da própria UFPA - para acolher doutorandos provenientes do Estado do Maranhão, Pará e Amapá, Estados vinculados a este Polo Acadêmico.

O Polo Acadêmico UEA, sediado em Manaus, que mantém experiência pós-graduada ainda incipiente, relativa ao Mestrado Profissional - recentemente transformado em Acadêmico - na área de Ensino de Ciências e Matemática, responsabiliza-se pela congregação formada por docentes doutores dos Estados do Acre, de Roraima e do Amazonas, dos quais participam as seguintes IES: UFAC (AC), UFRR e UERR (RR), UFAM, IFAM, UNINILTON e UEA (AM).

O Polo Acadêmico UFPA - do Estado do Pará - é considerado de maior experiência pós-graduada na Região Norte, posto que mantém, há mais de uma década, Programa de PósGraduação em Educação em Ciências e Matemáticas, com um Mestrado stricto sensu que titulou mais de uma centena e meia de mestres na Área, e que, no presente, é o único Programa de Pós-Graduação ao nível de Doutorado, em vias de titular os seus primeiros doutores diferenciados em qualidade.

\footnotetext{
${ }^{9}$ No presente exercida por doutores vinculados à UFMT.
} 


\section{O CULTIVO DOUTORAL SEM CESSAR NECESSITA PROVAR PARA PROVAR- $\mathrm{SE}^{10}$}

Para o delineamento do Programa de Doutorado em Educação em Ciências e Matemática, em desenvolvimento em REDE tal como assinalado, levaram-se em conta os requisitos, as necessidades e os interesses advindos da posição geográfica e do contexto sóciopolítico atual da Região Amazônica que possibilitam enunciar os seguintes pressupostos:

1. O caráter de urgência de ações da Ciência e da Educação em Ciências para o desenvolvimento da Amazônia.

2. O reconhecimento de que Ciência, Educação, Tecnologia e Inovação são imprescindíveis para o desenvolvimento regional sustentável, especialmente pelas exigências do século XXI.

3. A produção da Ciência e da Tecnologia associada às questões sócio-ambientais como imperativo para qualificar e titular profissionais em níveis diferenciados de qualidade, buscando termos os mais elevados de competência em âmbito acadêmico, científico e pedagógico para a Região.

4. As parcerias entre IES da Região que atuam no campo da Pesquisa e da PósGraduação consideradas fundamentais para viabilizar e acelerar a ampliação, em escala geométrica, de recursos humanos qualificados em nível de Doutorado, sobremaneira necessárias ao desenvolvimento da Região Amazônica.

5. As formas de conexão e articulação regionais, profícuas na Amazônia, que podem ser viabilizadas e potencializadas com a criação de redes interinstitucionais em áreas estratégicas, como a de Educação em Ciências e Educação Matemática, voltadas para o cenário de Sustentabilidade Ambiental, do Ensino e da Pesquisa em Educação das Ciências na Amazônia.

Sendo assim, tomamos como base institucional e de apoio acadêmico, científico e pedagógico o seguinte:

- A experiência - tanto em termos ainda incipientes de algumas IES pela recenticidade da proposição, quanto pela solidez de programas de pós-graduação das Instituições Associadas, já estabelecidos e plenamente avaliados, no âmbito de programas na Área de Educação em Ciências e Matemática, ou de programas afins, bem como os existentes até na área de Educação;

- A participação institucional em áreas de concentração ou em linhas de pesquisa destacando-se os termos de atuação das seguintes IES:

i) Da UFPA que, desde 2002, mantém Programa de Mestrado Acadêmico na Área de Educação em Ciências e Educação Matemática ${ }^{11}$ tendo titulado, até o início de 2012, cerca de duas centenas de mestres na área;

ii) Da UFMT que, desde 1989, mantém Programa de Mestrado Acadêmico em Educação, com linha de pesquisa em Educação em Ciências ${ }^{12}$, tendo

\footnotetext{
${ }^{10}$ Parafraseando Gaston Bachelard.

${ }^{11}$ Nota 4 na CAPES nas últimas avaliações.

${ }^{12}$ Nota 4 na CAPES nas últimas avaliações. 
titulado cerca de 80 mestres na área de ciências e matemática nesse período; e

iii) Da UEA que, desde 2006, mantém Programa de Mestrado Profissional na Área de Ensino de Ciências e Matemática, ainda com avaliação incipiente pela recenticidade da experiência e das ações de docência e pesquisa na Área.

- As experiências de interação institucional por meio de programas eventuais tais como Minter e Dinter, já desenvolvidos ou em desenvolvimento em algumas dessas IES;

- A experiência de grande parte dos docentes das IES associadas como formadores de professores - Mestres e Doutores - nas Áreas de Educação em Ciências e Educação Matemática para a Educação Básica e para o Ensino Superior (formadores-de-formadores);

- A produção de conhecimentos na Área, relativos à Região Norte, em função de frequentes Programas de Ensino e Pesquisa em Educação em Ciências da Região nos quais os doutores-formadores têm atuado.

Da criação do Doutorado em Educação em Ciências e Matemática, inicialmente pela ação conjunta em REDE e, posteriormente, pelo comprometimento assumido institucionalmente pelas IES associadas em continuar a formação em âmbito próprio ressaltam-se diversos fatores, dentre esses os que são explicitados a seguir:

a) Pela implantação e implementação de políticas públicas que visam o desenvolvimento regional (PAC, Acelera Amazônia, dentre outros), que pressupõem profissionais qualificados na área de Educação em Ciências e Matemática, para a devida compreensão das relações entre Ciência, Tecnologia, Sociedade e Ambiente das novas gerações de professores e estudantes;

b) Pela existência de dados que evidenciam discrepância regional - na relação que se estabelece entre a Região Norte e as demais do País -, principalmente no que diz respeito a indicadores de competência científica, tecnológica e pedagógica em Educação em Ciências e Matemáticas;

c) Pela insuficiência de professores da Educação Básica na Área. Segundo dados das Secretarias de Estado de Educação dos Estados da Região Amazônica, há grande demanda de formação, em nível de graduação, de professores de Matemática, Química, Física e Biologia. Embora as IES da Região venham investindo há décadas na interiorização de cursos e programas de formação de professores para o Ensino Básico, cerca de 50\% dos docentes que ensinam Ciências e Matemática na Região Norte ainda carecem de formação superior. Para ampliar o acesso, criando novos cursos de Licenciatura e para aprimorar esta formação, torna-se imprescindível o aumento do número de doutores que atuam nas Licenciaturas da Região, e de cursos correlatos de nível superior, que poderão determinar futuros cursos de pós-graduação stricto sensu (mestrado profissional, mestrado acadêmico e doutorado).

d) Pela carência nesta Região de professores formadores de professores e de pesquisadores com Doutorado na área de Educação em Ciências e Educação Matemática. As ações empreendidas pelas IES associadas para suprir seus quadros de doutores na área, tais como concursos públicos, contratos de professores visitantes, dentre outras, ainda são demasiado restritas para atendimento da demanda emergente e sempre crescente. Tanto é assim 
que passam, com frequiência, a ministrar aulas em cursos de formação, professores que não são das universidades e formaram-se em nível técnico. Vale ressaltar, ainda, os paliativos advindos das ações do PARFOR que têm como objetivo formar professores que já estão em sala de aula e não tem graduação como "primeira Licenciatura" ou carecem de uma "segunda Licenciatura" porque são os professores que tem uma graduação e ensinam disciplina de outras áreas para as quais não se encontram habilitados.

e) Soma-se a isso a insuficiente disponibilidade de doutores pesquisadores nestas Áreas no País, bem como o limitado número de vagas oferecidas em programas de pós-graduação em linhas de pesquisa como as que são enfocadas, nas várias universidades brasileiras. Em que pesem altos custos de deslocamento e manutenção de candidatos da Região Norte para freqüentar programas do Doutorado em outras regiões, mesmo assim, estes não seriam suficientes para suprir as necessidades existentes em médio prazo. Em função deste "estado de coisas", as IES da Região abrem concurso para doutores em Ciências e Matemática, e como não aparecem candidatos, alguns Reitores ${ }^{13}$, para suprir as lacunas, autorizaram/autorizam a realização de concursos para os professores já titulados como mestres, com o compromisso de que tão logo esses professores sejam contratados vinculem-se aos poucos programas de doutorado existentes na Área ou em Áreas afins, dentro ou fora do Estado. Decorre, pois, dessa situação, a necessidade de se formar - para esta Região e nesta Região - docentes doutores que, como profissionais ainda iniciantes pela titulação ou pela qualificação - já atuem nas licenciaturas e em outros cursos superiores desta Área e que, sem dúvida, aqui mantenham suas raízes.

f) Pelos baixos indicadores apresentados em alternativas de avaliação de qualidade, tais como na "Provinha Brasil" e no ENEM, que evidenciam, indubitavelmente, tanto a baixa quantidade quanto a baixa qualidade da formação de professores. Por isso, os diagnósticos realizados junto às Secretarias de Educação encarecem a urgente necessidade de as IES intervirem também no processo de formação continuada dos professores em exercício na Educação Básica desta Área. Os novos doutores nas IES da Região que desejamos formar - desde que em número ampliado e com formação específica na área - certamente criarão Grupos de Estudos e Pesquisas em Educação em Ciências e Matemática nos diferentes Estados, para estabelecerem novas relações formativas nas IES, bem como outras condições de visibilidade na Área. Isto poderá produzir respostas positivas e desejáveis em cada uma das Instituições, confrontando não só a Educação Superior, mas também a Educação Básica.

g) Pela discrepância intra-regional de distribuição dos poucos doutores existentes na Área de Educação em Ciências e Matemática, e afins, dispersos nas diversas IES da Região, vez que se encontram distribuídos em um imenso território geográfico. Por vezes, a baixa concentração de doutores da Área, em determinado Estado, provoca isolamento maléfico desses doutores, dificultando e impedindo a interação necessária para a produção e divulgação científica, bem como para o exercício das demais funções doutorais;

h) Pela insuficiência de programas de doutorado na área específica para suprir as demandas nacionais de formação de professores pesquisadores atuantes nas licenciaturas e em outros cursos superiores das IES associadas. Vale assinalar

\footnotetext{
${ }^{13}$ Como foi o caso do Ex-Reitor da UFPA, Prof. Dr. Alex Fiúza que introduziu esta prática que vem se cultivando na Universidade.
} 
que, na Região da Amazônia Legal, em que pese a imensa área geográfica que a constitui, há apenas UM curso de doutorado na Área. Isto determina, certamente, urgência para um Programa de Doutorado mais abrangente, agora em funcionamento, para que se produza o salto de qualidade pretendido na formação docente nas IES da Região e na produção de conhecimento na Área de Educação em Ciências e Matemática;

i) Pela dificuldade de fixação de doutores na Região Amazônica, quer pela escassez desses profissionais no País quer pela inexistência de atrativos da carreira para a fixação profissional nesta Região, uma vez que os salários das instituições públicas são considerados sobremaneira baixos. Faz-se, portanto, necessária a formação de doutores da Amazônia na Amazônia, gerando a tão desejada fixação de especialistas e titulados de alto nível na Região Norte;

j) Pela disposição das IES desta Região em se associar organizando seus docentes doutores, com o intuito de superar ou, pelo menos, atenuar, de forma colaborativa, as dificuldades e as carências enunciadas. Em vários Estados, a organização das IES em protocolos de cooperação interinstitucional tem sido uma prática há mais de uma década, e isto tem favorecido o desenvolvimento de projetos e programas que, de forma isolada, seriam inviáveis;

k) Pela necessidade de instalação de novos programas de Mestrado Acadêmico e Profissional na Região, os quais tornarão possível a continuidade da formação de DOUTORES na Área de Educação em Ciências e Matemática com a participação e o envolvimento daqueles que já se encontram em IES desta Região. A implantação deste Programa de Doutorado por associação em REDE parece ser a forma mais rápida e econômica para a implantação, em prazo mais curto, de Programas de Mestrado Acadêmico e Profissional nos Estados e nas IES da Região Amazônica, possibilitando que esta Região venha a assumir outro patamar de qualidade na formação de professores de Ciências e Matemáticas na Educação Superior e, subsequentemente, na Educação Básica.

Justamente nesse sentido, a proposta de Doutorado em REDE tem se apresentado como possibilidade ímpar de titular doutores formadores de professores e pesquisadores nas relevantes Áreas de Ciências e Matemática, por meio de cujas pesquisas e atuação na formação inicial e continuada, bem como na educação informal, poderão diagnosticar e intervir na realidade da Região Amazônica. Sendo assim, certamente poderão contribuir para a construção de conhecimentos específicos neste âmbito ao preparar profissionais qualificados em diversos níveis para atuar, de forma profícua, sobre e na Região Amazônica, com vistas ao desejável desenvolvimento regional, ao tempo em que enseja justiça social.

Em outros termos, temos trabalhado para, certamente, poder atuar, em termos potencializados, (i) na Educação Básica, (ii) na produção de conhecimentos necessários ao desenvolvimento regional, (iii) na construção da autonomia intelectual de doutores - na docência e na de pesquisa -, mas, sobretudo, (iv) na competência específica de professores e pesquisadores com qualificação doutoral em Educação em Ciências e Matemáticas da Região Norte.

Embora seja desejável um Programa dessa natureza voltado prioritariamente para a formação de profissionais para a Educação Básica, assumimos que o primeiro grande esforço de assegurar competência científica específica deva ser dirigido à formação de docentes doutores - formadores-de-formadores e de doutores-pesquisadores - que atuam no Ensino Superior da Região. Pretendemos, assim, formar doutores na Região e para a Região, vale reiterar, fixando-os neste espaço geográfico, para que, em médio prazo, possamos atingir a 
imprescindível competência doutoral na Amazônia, em proporção tal que se possa propor e manter programas de elevado nível de qualidade em novos mestrados profissionais e acadêmicos nos vários Estados. Esperamos, pois, em prazo médio, oferecer à comunidade da Região Amazônica novos Programas que sejam atinentes ao Stricto Sensu de Mestrado e de Doutorado, como forma de contribuir para a formação de docentes-doutores qualitativamente diferenciados para o aprimoramento continuado da docência e da pesquisa em diferentes níveis de Ensino.

\section{A CONDUTA DOUTORAL OBJETIVA ESTAR EM LUTA COM OUTROS E CONSIGO MESMA ${ }^{14}$}

Os objetivos desta pesquisa advêm da necessidade de investigar, continuadamente, as formas de cultivo doutoral nas ações e atitudes de doutores já atuantes em outras áreas ditas "duras" e que migram para a Área de Educação em Ciências e Matemática, com o propósito de assumir em colaboração a formação de Doutores em Educação em Ciências ou em Matemática, que se quer destacados em elevado nível de atributos de qualidade científica e pedagógica, tal como se expressa na proposição que constitui a REDE. Isto significa abrir espaço acadêmico para investigar a migração e a conduta de doutores das áreas das Ciências e das Matemáticas nas suas formas "puras" ou "duras", e de outras afins, para a Área de Educação em Ciências e Matemática, em razão da criação de interesse e de disponibilidade para colaborar - em parceria - tendo em vista a realização dos propósitos definidos de qualificação doutoral para melhor.

Esses doutores credenciados há dois anos neste Programa de Doutorado em REDE ${ }^{15}$ passam, portanto, a ser investigados - nos termos da modalidade investigativa-narrativa da pesquisa qualitativa à luz de fundamentos epistemológicos, teóricos e metodológicos da docência e da pesquisa - em seus processos de adesão e de resistência, como se disse, especialmente em relação ao seguinte:

i) Sua participação como docentes-pesquisadores titulados formando doutores de qualidade para este século e gerando produção acadêmica nas Áreas enfocadas, bem como

ii) $\quad \mathrm{O}$ fornecimento - ou não - de evidências de interesse e comprometimento como Doutores em exercício na formação de novos doutores, quer pela qualidade do Ensino Superior no qual atuam, quer pela melhoria de qualidade do Ensino Básico, justamente na Educação em Ciências e Matemática.

Objetivamos estabelecer novas relações formativas nas IES para ensejar visibilidade para a Educação em Ciências e Matemática sob enfoque, de forma tal que possam ser produzidas respostas/alternativas positivas não só no âmbito do Ensino Superior, especialmente na Pós-Graduação, mas também no que se apresenta como desejável para aprimorar as ações docentes, científicas e pedagógicas no Ensino Básico deste País.

De outra forma, é nosso objetivo investigar em que termos repercutem junto a professores-doutores no exercício da docência e da pesquisa, nas IES associadas em REDE,

\footnotetext{
${ }^{14}$ Parafraseando Gaston Bachelard.

${ }^{15}$ Referimo-nos ao tempo de credenciamento na REAMEC. 
proposições teórico-metodológicas e epistemológicas do presente vinculadas a um saberfazer positivamente diferenciado nas abordagens científico-pedagógicas da formação doutoral considerada desejável para este País neste século.

Isto implica intensificar o debate científico associado aos saberes da docência, à profissionalização docente e às funções de produção e socialização do conhecimento por meio da ação colaborativa entre IES - e entre a Universidade e a Escola Básica - com o envolvimento de profissionais doutores qualificados e titulados, e já em exercício.

Em termos específicos,

- intenciona-se propiciar espaço de manifestação de professores-doutores e pesquisadores já titulados em Ciências, Matemáticas, Tecnologias, e mesmo em Educação, com o propósito de verificar seu nível de compreensão de processos acadêmicos de ensino e de aprendizagem para aquisição de conhecimentos científicos e pedagógicos diversificados. Isto para que estes possam compreender para abolir a visão dualista e hierárquica entre saberes e práticas docentes dissociadas, substituindo-a por outra visão posta numa perspectiva político-epistemológica que enseje explicitar que nenhuma sociedade é capaz de pensar a si mesma sem a "religação" dos saberes e práticas de suas instituições educacionais.

Nessa perspectiva, vale aspirar a "um mundo melhor e mais fraterno", principalmente na interação científico-pedagógica que se dá entre professores-doutores e estudantesdoutorandos, ao tempo em que se consideram as diferentes e diversas possibilidades autoorganizativas (PRIGOGINE, 1996) que o Homem ainda está aprendendo a desenvolver e explorar. Possibilidades essas geradas em meio ao conflito e à instabilidade, ao fim das certezas, à tensão entre ordem-desordem-nova-ordem, à complexidade, e a tantas outras facetas que caracterizam o mundo deste século.

Pretendemos, pois, trazer à tona perspectivas metodológicas emergentes em função da experiência e da prática dos sujeitos-acadêmicos doutores em "áreas duras" que integram esta experiência no âmbito do ensino das ciências com que lidam - e que se dispuseram a migrar para ou associar-se a Educação em Ciências e Matemática - buscando configurar em parceria um campo de projeções de construção de um futuro profissional de professoresdoutores diferenciados para melhor.

Uma construção feita de liberdade, de criatividade, de ideais e sonhos postos numa postura qualificada em termos pós-graduados de doutores que expressem conduta e nível doutoral em suas ações e reações científico-pedagógicas no curso da formação de novos doutores para esta Região e este País.

\section{OS PERCURSOS DA INVESTIGAÇÃO}

No âmbito desta investigação, e deste estudo, expressamo-nos ora na primeira pessoa do singular ora do plural em termos de tratamento lingüístico. Tal tratamento ocorre não só para explicitar nossas ações e reações como pesquisadores-parceiros - doutores e doutorandos, individuais e coletivos - que optam por um percurso investigativo de natureza qualitativa, na modalidade narrativa, mas também assumindo tal modalidade como atitude de investigação e modo afetivo e efetivo de expressão. Isto porque, na perspectiva posta por Aragão (2006), assumimos a modalidade narrativa de investigação quer como parâmetro de 
qualidade investigativa que estrutura experiências docentes para estudo, quer como designativa dos padrões de investigação que vão ser utilizados para estudo da experiência.

Assumir a narrativa como procedimento usado para investigar visões e ações docentes em relação à Educação em Ciências e Matemática implica, tal como expressam McEwan \& Egan (1995), reconhecer seu papel fundamental para o propósito de comunicar quem somos, o que fazemos, como nos sentimos e porque devemos seguir certo curso de ação e não outro.

Nessa perspectiva, narrar pode servir ao propósito de exteriorizar aos outros - ao explicitar sentidos e significados - o que já se faz presente no campo subjetivo, isto é, no interior da consciência de cada um e cada qual, onde habitam ideias, intenções, reflexões, sentimentos e aspirações.

Assim, sob a forma de narrativas do presente, os sujeitos-professores-doutores e pesquisadores desta pesquisa, sobretudo, aqueles advindos das várias IES dos Estados que constituem a Amazônia Legal, podem exteriorizar ideias e proposições - ou em termos públicos ou privados - que expressam o futuro, quer com conotações céticas quer utópicas. Dessa forma, podem submeter à consideração investigativa um conjunto de relações de sentido ligado à transformação de si como professor e pesquisador, bem como à implantação e ao desenvolvimento da Educação em Ciências e Matemáticas nesta Região.

Em busca de captar apreensões do presente que podem expressar e delinear um devir da Educação na Área sob enfoque, optamos por coletar as vozes dos sujeitos-doutoresmigrantes desta pesquisa sob a seguinte forma:

- Manifestações e expressões ao vivo capturadas e registradas em diário de campo da pesquisadora e de doutorandos presentes ao evento fundamental da REDE em que as ouviram, relataram convenientemente e registraram-nas conjuntamente.

As enunciações dos professores-doutores que se tornaram sujeitos desta investigação se deram no curso das avaliações de projetos apresentados por doutorandos em seminários específicos $^{16}$, com uma constituição definida, qual seja, com a presença do orientador da tese em pauta, de dois professores-doutores avaliadores inter áreas de concentração, bem como com a participação de um doutorando que, em cada exposição, exerceu a função de "debatedor".

Nos registros dos diários de campo - por parte da pesquisadora - a atenção foi, sobretudo, dedicada a questões epistemológicas cruciais para a docência e a pesquisa em Educação em Ciências e em Educação Matemática. Estas foram postas diretamente por perguntas simples ou emergiram em manifestações e expressões, como dissemos, de doutores examinadores e avaliadores que assumiam a posição de "responsáveis pela atribuição de valor aos projetos de tese ou trabalhos já em andamento de doutorandos participantes".

Ao procederem a avaliação do trabalho/da tese em pauta, os doutores tratavam de afirmar suas posições acadêmicas, principalmente nas discordâncias da forma posta, assumida e expressa na projeção apresentada ou na pesquisa que havia sido recém iniciada. No curso da vivência dessas interações, pudemos nos dar conta do descompasso que tem havido entre ideias, concepções, abordagens científicas, epistemológicas e metodológicas, e até mesmo de 'visão de mundo' entre os professores-doutores migrantes para a nova Área, justamente pelo fato de não se assumirem do ponto de vista da Educação em Ciências e Educação Matemática, nos termos da proposição da REDE.

\footnotetext{
${ }^{16}$ O evento aludido foi o I Seminário Curricular da REAMEC realizado em período recente.
} 
O critério de seleção dos sujeitos professores-doutores migrantes de áreas "duras" ou afins ${ }^{17}$ se fundou, vale reiterar, na sua disposição e disponibilidade de credenciamento na REDE para participar da interação em parceria que ora se põe na docência de disciplinas, ora em atividades de orientação de TESE e, certamente, em encontros para estudos e pesquisas que possam realizar-se periodicamente nas IES às quais os profissionais se vinculam.

Desse modo, com base em observações assistemáticas que alguns dos membros da REDE puderam fazer, registramos os diferentes discursos manifestos, com a intenção de lidar dialeticamente com relações compreensivas do tipo 'pontos-e-contrapontos', 'construção-edesconstrução', em função de ações e reações expressas.

De início, buscamos deflagrar um processo de mobilização das ideias nucleares dos sujeitos professores-pesquisadores acerca de aspectos da Educação em Ciências e Matemáticas que expressam seus posicionamentos teórico-metodológicos e epistemológicos fletidos, refletidos e discutidos no contexto da interação grupal do seu Polo Acadêmico. Desse modo, decidimos trazer à tona seus referenciais para dar sentido ao que, no modo de ver deles próprios, geram impacto sobre eles mesmos e suas práticas educativas em termos de teorias e metodologias fundantes de seu saber-fazer docente no momento presente.

Nessa perspectiva, vamos tratar das vozes dos parceiros, expressas em grupo, em evento público, como é o caso, e em textos reflexivos, sob a forma de sínteses narrativas que, no dizer de Carniatto e Aragão (2003:02) - em correspondência com episódios narrativos - são "recortes" passíveis de comunicar os sentidos atribuídos pelos enunciantes quando estes refletem sobre a complexidade da realidade vivida e sobre uma realidade complexa sob enfoque e em projeção.

A partir dessas opções, intensificamos nosso mergulho no material empírico já acessível para definir critérios de análise, que implicam a observação das recorrências, ou seja, da reiteração de ideias, reflexões e abertura de perspectivas que tendem para um ponto de confluência. Nesse processo, nos detivemos na consideração, de um lado, das comunalidades, ou seja, de aspectos que os diferentes parceiros apresentam em comum em suas ideias e falas e, de outro lado, das divergências e contradições entre suas ideias e posicionamentos manifestos.

Certamente, em função dessa dinâmica interativa e colaborativa, podemos construir textos/artigos/comunicações acadêmicos, de natureza científica e pedagógica, para expressar nossas mudanças e nossos avanços acadêmicos, sobretudo os de natureza políticoepistemológica, de forma tal que - organizados em coletânea - possam ser dados a público e ao conhecimento dos nossos pares de qualquer área de conhecimento.

\section{CALÇOS E PERCALÇOS DA FUNDAMENTAÇÃO TEÓRICA}

Aborrecimentos ou desgostos naturais em uma atividade ou empreendimento configuram contratempos, deslizes no percurso normal da coisa, mas não podem ser impeditivos de que os propósitos, os desideratos, sejam atingidos.

17 - Oriundos dos NOVE Estados da Amazônia Legal e das 25 IES associadas . 
A colaboração ou parceria interinstitucional na formação de professores qualificados e titulados, principalmente em nível doutoral, é uma tendência teórico-prática em pleno desenvolvimento em vários países (Tardif et al., 1991, e Smedley, 2001).

Embora paire sobre esta abordagem interativa certa apreensão dada a imprevisibilidade da inovação que lhe é inerente, posto que não é possível precisar seu futuro, quer dizer, até onde irão chegar seus rumos e resultados, vale a pena confrontar posições e ideias acadêmicas que dela decorrem, com freqüência, de forma proveitosa.

- Que tensões essa nova modalidade de ação potencializa entre os sujeitos sociais e institucionais envolvidos?

- Que rupturas ou bloqueios estão sendo engendrados e como estes se refletem no processo de formação e profissionalização de docentes-doutores?

Tanto professores-doutores de IES quanto professores de Escolas Básicas defrontamse, com freqüência, com situações para as quais não se sentem preparados, uma vez que não dominam o terreno de ensino/pesquisa onde estão pisando, trazendo-lhes incertezas diante dos múltiplos desafios que surgem a cada novo passo que é dado (Contreras, 1997; Perrenoud et al., 2001 e Lüdke, 1999). Quando se fala em 'professor-reflexivo', por exemplo, se pode estar lidando com uma questão ainda imprecisa e não claramente definida (Contreras, 1997). Daí a importância de certa vigilância, com o aprofundamento de problemática como esta, por meio de pesquisas e experiências concretas inter pares tal como se busca realizar há mais de dois anos na REDE de ações, reações e atitudes para formar doutores.

Daí decorre a nossa preocupação, por analogia, com o CULTIVO DOUTORAL, assumindo ser esse processo que configura a primeira rede de competentização e qualificação coletiva de projetos de formação de doutores (na alternativa financeira designa-se por crowdfunding $^{18}$ ) associada às leis de incentivo financeiros - também intelectuais - do Brasil. Nesse âmbito, empresas e pessoas poderão exercer seu direito de colaborar investindo em iniciativas inspiradoras ${ }^{19}$ e até mesmo de suportar custos de qualificação doutoral e pósdoutoral de profissionais de quaisquer áreas. O CULTIVO como rede de ações intelectuais contribui com cada um e cada qual nesta DECISÃO de ampliar os horizontes de professores do ensino superior e dar maior amplitude à sua visão de Educação, no nosso caso, de Ensino e Pesquisa em Educação em Ciências e Matemática!

Vale assinalar que tal visão insiste em desconsiderar um professor do ensino superior limitado a ser simples "repassador" ou apenas "transmissor" de conhecimentos produzidos fora de sua profissão, como assinalam Nóvoa (1992a e 1992b) Zeichner (1987, 1992a e 1992b), Santos (1991), Perrenoud (1993 e 2001) e Lüdke (1998b). Isto porque essa atitude reforça a racionalidade instrumental ou técnica do ensino e da pesquisa em Educação em Ciências e Matemática, cuja epistemologia emerge como insuficiente para abarcar e entender as relações que se imbricam na compreensão básica de que o trabalho docente, geralmente, desencadeia processos complexos de elaboração teórico-prática, e de saberes próprios dos profissionais do ensino e da pesquisa, principalmente de professores-doutores.

$\mathrm{Na}$ esteira dessas articulações, a ideia de 'construção' implica relações de muito maior complexidade, por isso, à luz de Bachelard (In BULCÃO, 2009) rompeu-se com a noção de dado, evidenciando que - na ciência contemporânea - o que se designava como

\footnotetext{
${ }^{18}$ Ver o site wwW.cultivo.cc

19 No caso específico de crowdfunding é possível até deduzir o valor financeiro investido do Imposto de Renda devido ao governo, exatamente como já fazemos com nossas despesas médicas, odontológicas, entre outras.
} 
"dado" no século passado já é resultado obtido através do diálogo entre razão e experiência no tempo presente.

Ressaltamos, entretanto, que a concepção de ciência como construção confere novo estatuto à noção de sujeito. Como o conhecimento se constitui através da retificação do saber anterior na interação social, como podemos invocar e assinalar em Vygotsky, a função primordial do sujeito é "se enganar", por isso é passível de compreensão a noção de erro. Sendo assim, não tem sentido, pois, falar de um sujeito que antecederia o ato de conhecimento. Para Bachelard, o sujeito se elabora no trabalho, constitui-se durante o processo cognoscente, justamente através do exercício da 'função retificadora' de seus sentidos e significados. A despeito da importância de um professor-doutor conhecer tais ideias, essas posições e proposições não parecem interessar a muitos dos professores-doutores "duros", posto que estes, quase sempre, nem parecem ter ideia do que se trata.

A soma de esforços interinstitucionais - através de programas de parceria favorece, no entanto, uma maior e necessária articulação entre saberes teóricos e saberes da experiência. Esses se configuram justamente em termos do "saber anterior", cuja antinomia vem, ainda, rendendo acalorados debates entre os profissionais do ensino de modo geral, expressos por Tardif \& Lévesque (1998) e Tardif et al. (2001), dentre outros.

Contudo, esses se tornam antagônicos a visões e admissões de ideias ou concepções tais como as seguintes:

- a da "defesa pública da neutralidade da ciência” (Cf. manifestação do Dr. $4^{20}$ );

- a de subestimação de práticas científico-pedagógicas e do desabono das práticas pedagógicas ou culturais que implicam 'saberes teóricos' e 'saberes da experiência' porque, no modo de ver do doutor, estas "nãa são ciência".

Tais manifestações são/foram apresentadas, simplesmente, como argumentos de autoridade, sem qualquer argumentação adicional, postos justamente por aqueles que não só estudam pouco para serem tomados como exemplos, mas também desenvolveram pesquisa restrita e parecem desconhecer a importância da contextualização sócio-cultural ou científicopedagógica.

Na discussão sobre 'Universidade', os autores antes referidos afirmam que esta tem seus benefícios na medida em que encontra alternativas para incorporar novos saberes ao seu projeto de formação inicial e continuada de professores, de recém doutores, pesquisadores ou de quaisquer profissionais. Tratam-se de saberes da experiência e da prática docente produzidos no interior e em função da indissociação da relação sujeito-objeto - negada peremptoriamente pelo Dr.3 em público ${ }^{21}$ - sem argumentação plausível, sem projeção de qualquer ganho ou avanço no contexto específico.

No bojo desses debates, há questões que não devem passar despercebidas, não só pelo anacronismo, mas também pelo "teor de verdade com que são ditas", acrescidas de certa arrogância doutoral que não mais se admitem sem argumentação científica e sem pretensões de "verdade" em função de reflexões do presente. Essas estão claramente postas no discurso doutoral expresso recentemente, cuja síntese se põe em vários dos termos seguintes:

- Dificuldades de configuração do objeto epistemológico de uma pesquisa ao debater/avaliar um projeto de pesquisa para uma tese de doutorado (Cf.

\footnotetext{
${ }^{20}$ Atribuímos um código de referência aos professores-doutores que se manifestaram nas sessões do evento enfocado, considerando a ordem de manifestação: o Dr.4 foi o quarto manifestante de sua categoria a se manifestar.

${ }^{21}$ Quando do I Seminário Curricular da REAMEC realizado em Belém do Pará, em termos recentes.
} 
manifestações do Dr.3). Para este doutor parece existir apenas UM “ jeito isento” para tanto;

- Dificuldades de reconhecimento e enunciação de uma tese (Cf. manifestações do Dr.5). Para este, a ideia de TESE não se explicita nem sequer pela relação "experimental" - usada por ele - com hipótese, nem tão pouco pela relação hipo+tese;

- Dificuldades de deixar claro o delineamento, quer dizer, a explicitação do desenho teórico-metodológico de uma pesquisa (Cf. Dr.2). Para este e outros dois doutores-formadores a explicitação do desenho é apenas a de um "sumário", não havendo necessidade de explicitação de problema, mas apenas de um 'tema' e da projeção de capítulos que comporão o relato para deflagrar uma "pesquisa científica";

- Mensuração ("medição") de eventos da educação em nome da "isenção pela matematização da ciência pura" é o que valida uma tese (Cf. Dr.5);

- Utilização de formas de mensuração externas, sobretudo de testes estatísticos para atribuir valor de verdade a processos de Ensino e de Aprendizagem (Cf. Drs. 5 e 6$)$.

Em razão de limitações, restrições e distorções como essas, de natureza positivista aos moldes do século passado (e muitas do Século XIX), como revelam manifestações supostamente doutorais de vários dos integrantes da REDE, as instituições formadoras de profissionais do ensino, e mesmo de outros profissionais, de modo geral, ainda continuam pensando e expressando, por meio de seus representantes, os currículos de formação em forma de "menus" ou "catálogos" - ainda falam simplesmente de "grade"22 - os quais, em momentos de reformas, sofrem apenas pequenos arranjos, demasiado superficiais e artificiais, que deixam de afetar tanto a relação básica de teoria-e-prática, quanto as concepções epistemológicas nas quais se fundam os currículos, mantendo-se como vinham sendo "desde sempre". As mudanças e transformações ideacionais se situam e se envolvem também nesses termos, tal como expressam os doutores-formadores-de-doutores sob consideração.

Nesse sentido, temos assumido com Morin (2005), a posição acadêmica que este autor considera como utopia realista, localizada no terreno das possibilidades concretas (no sentido marxista), ainda que, no presente - vista a distância de forma apenas contemplativa pareça irrealizável. Utopia na qual situamos o saber-fazer docente do professor-pesquisador de uma formação diferenciada, justamente no Doutorado em Educação em Ciências e Matemática, que se evidencia formação transformadora a serviço da educação de cidadãos críticos e felizes.

Demarcamos, ao final, conceitualmente, o sentido de 'utopia' para expressar a imagem e representação de um mundo melhor - ainda que não perfectível - mesmo tido como ainda irrealizável no presente. Tal imagem encerra a capacidade de mobilizar esforços para uma ação transformadora da realidade atual, na medida em que provoca um desejo de reconhecer para superar o que se põe como medíocre, como obsoleto ou anacrônico, para construir algo diferente do status quo, do real, para melhor.

\footnotetext{
${ }^{22}$ Raros são os professores-doutores que se manifestam capazes de descartar esses termos redutores e de explicar com clareza a razão da rejeição desses sem que se refiram a e afirmem "modismos".
} 


\section{A CONDUTA DOUTORAL DESTA VEZ TEM GARANTIAS DE SER INCISIVA ${ }^{23}$}

É possível destacar, em função de nossas expectativas, tanto (i) a apropriação do uso pedagógico das tecnologias vinculadas à Internet no Ensino e na Educação das Ciências e da Matemática, quanto (ii) o sentido e os significados do saber-fazer docente e de pesquisa para a Educação em Ciências e Matemática como cerne da transformação da prática docente no Ensino Superior e na Educação Básica. Tais ações e reações são supostas de estar também presentes na atitude e na conduta dos professores-doutores migrantes para as Áreas assinaladas.

Entretanto, tais "produtos" não podem ser ditos suficientes para que a Educação/Ensino das Ciências e da Matemática (e mesmo das Tecnologias) se modifique em termos abrangentes, eloquentes e significativos. Além disso, certamente, é preciso desencadear um processo amplo e multidimensional de mudanças que atinja vários setores e sujeitos implicados nas IES que constituem ou se encontram associadas à REDE para formação de doutores.

Contudo, no processo mesmo de significação da prática docente deste século, é possível obter retorno positivo de professores-doutores e pesquisadores do ensino superior advindos de áreas ditas "duras". Desde que estes profissionais passem a se empenhar para superar a lógica de organização que parece congelar o ENSINO e a PESQUISA EM EDUCAÇÃO EM CIÊNCIAS E MATEMÁTICA. Tal lógica continua fundada no pensamento causal, na linearidade e na fragmentação positivista do conhecimento, muito embora se torne imprescindível assumir relações compreensivas para assegurar a melhoria de qualidade da formação profissional de estudantes da pós-graduação, sobretudo, de futuros doutores.

Nesses termos, é possível obter resultados importantes advindos do estabelecimento dessas relações compreensivas entre conteúdos/conhecimentos relevantes na Educação/Ensino de Ciências e Matemáticas e a realidade de professores-doutores, supostamente pesquisadores da Educação em Ciências e doutorandos no âmbito de uma REDE de formação doutoral.

Essa perspectiva implicará, certamente, grande esforço dos professores-doutores e pesquisadores migrantes de outras para a Área de Educação em Ciências e Matemáticas para conhecer e conscientizar-se das questões epistemológicas desta sua nova área de atuação profissional. Isto para que possam superar os tradicionais pressupostos de uma/sua formação positivista externalista e fragmentária, vale reiterar, largamente presente no processo de formação docente do século passado (XX) e ainda cultivada neste século (XXI) no que diz respeito, sobretudo, à seguinte assertiva:

- É imprescindível que professores-doutores passem a conceber outra/nova relação triádica professor-estudante-conhecimento, admitindo proximidade, interação e confiança entre esses sujeitos, sobretudo, para assunção de outra/nova postura ou conduta doutoral.

Nessa direção, os professores-pesquisadores titulados - especialmente os migrantes de outras áreas das ciências das IES envolvidos nesta REDE de formação doutoral de docência e pesquisa - precisam aprender a ensinar compreendendo a importância de se construir o ensino no seio da Educação em Ciências e Matemática de forma tal que o estudante/doutorando se

${ }^{23}$ Parafraseando Gaston Bachelard. 
constitua o centro da relação ensino-aprendizagem-conhecimento, tendo em vista aprimoramento da qualidade de sua formação profissional.

Trata-se, portanto, de conceber outro contexto de ensino - ausente das relações meramente burocráticas - no qual o aprendiz/aluno/estudante possa assumir, efetivamente, o papel de sujeito da sua própria aprendizagem, e o professor-doutorpesquisador o de mediador da construção do conhecimento realizada em parceria com o estudante.

Nessa perspectiva, visamos, pois, explicitar - pela investigação-narrativa - ganhos a serem obtidos concernentes a

(i) O estabelecimento e a compreensão de relações significativas nas ações de professores-doutores-pesquisadores para a formação profissional de novos doutores do tempo presente, bem como

(ii) A construção de outras/novas paisagens científicas, pedagógicas e tecnológicas nos processos de formação profissional doutoral.

Esses ganhos, sem dúvida, precisam ser construídos $\boldsymbol{e}$ re-construídos com base em novos/outros pressupostos teóricos e metodológicos do futuro que já é agora, que incidem sobre a constituição daquilo que o professor - titulado como doutor - faz do seu ensino e do que ele é como pessoa e profissional docente-pesquisador.

\section{FAZER DO INACABAMENTO ESSENCIAL DA CONDUTA DOUTORAL O ÍNDICE DA SUA PROGRESSIVIDADE ${ }^{24}$}

Os problemas mais comuns relacionados com os cursos e percursos doutorais são vários, contudo, a maior parte centra-se nos que dizem respeito e se relacionam à orientação da tese, isto é, imbricam-se ao orientador. Desde problemas com a concepção do projeto do problema e do objeto epistemológico da pesquisa - até com a redação final tornam-se cruciais justamente por falta de competência científica de quem orienta. Nas instituições do Exterior isto não acontece porque somente assume a orientação de uma tese quem é expert no assunto. De outra forma, considerando as diferenças na maior parte dos casos brasileiros, podemos ressaltar o seguinte:

(a) Fragilidade da relação entre orientador-orientando, como detrimento da capacidade de orientação do orientador, da sua falta de competência específica;

(b) Relações conflituosas entre orientador-orientando advindas de questões empáticas, de pouca afinidade com ou de insegurança acadêmica do orientador;

(c) Dilemas relacionados à falta de apoio técnico sem ajuda da orientação ao desenrolar do projeto;

(d) Dificuldades de delineamento claro do projeto, de organização da informação, de definição de critérios de análise e da redação final da tese, pelo abandono mesmo do doutorando ou pela precariedade da orientação;

(e) Tese com formato e tratamento de dissertação de mestrado dadas a restrição e a limitação intelectual por parte da orientação (orientadores tendem a "só saber fazer dissertação" e não parecem distinguir tese de dissertação em termos epistemológicos);

(f) Estresse frequente do orientando porque o orientador não lê e não acompanha o que já foi produzido, com a excusa frequente de não ser possível priorizar a(s) orientação(ões) por excesso de atribuições no seu espaço acadêmico. Parece ser uma estratégia comum para deixar o orientando sozinho e este ter de "se virar"...

\footnotetext{
${ }^{24}$ Parafraseando Gaston Bachelard.
} 
(g) Falta de feedback, em termos de estimulação mínima para prosseguimento do trabalho (ou somente se estimula quem não precisa...).

Há consequências sérias do ciclo de percalços que é atinente ao estresse ambiental e pessoal advindos desses descompassos. Várias áreas são afetadas e com repercussões duradouras. Além disso, o modelo doutoral que tende a ser incorporado é justamente o que se considera indesejável - pela fragmentação e segmentação - no presente e que desejaríamos superar para diferenciar em qualidade o doutor que queremos formar.

Antes de tudo, a qualidade dos trabalhos produzidos ao longo do percurso do doutorado pode ser severamente afetada por estratégias de enfrentamento pobres de questões que surgem, sobretudo, originadas da relação orientador-orientando. As estratégias de enfrentamento $^{25}$ são os esforços cognitivos e comportamentais para lidar com situações de dano, de ameaça ou de desafio, quando não está disponível uma rotina ou uma resposta automática, ou quando não se pode contar com apoio certo.

O risco maior, a nosso ver, é que os estudantes de pós-graduação - tanto mestres quanto doutores - se tornem especialistas sem perspectivas, que podem chegar a ter competência técnica, mas faltar-lhes capacidade reflexiva mais ampla. Este estreitar da visão conceptual dos outros e do mundo afeta diretamente a capacidade do futuro doutor vir a lidar convenientemente com problemas proativos do contexto laboral no qual se insere.

O curso e o percurso de Doutorado contêm muitas pressões que se irão encontrar no resto da carreira profissional, no entanto, esta afirmação é especialmente verdadeira para quem quer seguir a vida acadêmica.

É essencial, por parte do doutorando - com a ajuda de professores-doutores - o desenvolvimento de estratégias de enfrentamento eficazes enquanto está no curso mesmo do processo de formação, buscando outro tipo de interação inter pares e inter professoresorientadores, de modo a obter sucesso de uma maneira saudável, salvaguardando visões e posições fundamentais, não apenas para o processo de pós-graduação, mas também para etapas subsequentes de vida. A reação individual ao estresse e a habilidade para lidar eficazmente com as limitações e restrições cognitivas e científicas que lhes são postas pela incompetência ou "competência precária", com o abandono intelectual e com a insegurança acadêmica podem ser mais importantes do que simplesmente diminuir a carga de esforço, no curso do Doutorado.

Os calços do Doutorado, especialmente no caso da nossa REDE, precisam ser relativos à certa ampliação da visão da Educação em Ciências e da Educação Matemática, que impliquem o conhecimento e a compreensão da evolução contemporânea da relação dessas Áreas com outros saberes na escola e na sociedade.

O que se torna imprescindível marcar, de forma exemplar, como papel eminente deste Programa de Doutorado no panorama mundial - que todo professor-doutor formador deve conhecer - implica o estudo das condições e das limitações que determinam a crise histórica atual em países como o nosso. Essa crise incide sobre o ensino/a educação básica e o ensino superior/a educação universitária tanto dos saberes "clássicos" (desde as ciências físicas e químicas e a arqueologia passando pelas matemáticas) quanto dos saberes de constituição mais recente (a museologia ou o desenvolvimento sustentável, por exemplo).

Finalmente, essa crise a que nos referimos coincide com a subestimação, aparentemente sistemática, por parte de professores-doutores responsáveis pelas diversas áreas de conhecimento, pelos vários níveis de ação docente, bem como pelas abordagens de investigação científico-pedagógicas, que continuam a ser amplamente desconhecidas.

${ }^{25}$ Segundo a referência portuguesa (de Portugal). 


\section{REFERÊNCIAS}

ARAGÃO, Rosália M. R. de. Uma interação fundamental de ensino e de aprendizagem: professor, aluno, conhecimento. In: ARAGÃO, Rosália. M. R. de \& SCHNETZLER, Roseli P. (Orgs). Ensino de Ciências: fundamentos e abordagens. Campinas-SP: R.V. Gráfica e Editora Ltda.: UNIMEPCAPES, 2000.

Compreendendo a Investigação Narrativa de Ações Escolares de Ensino e de Aprendizagem no Âmbito da Formação de Professores. (2002). Disponível em http://www.anped.org.br/27/g08/t0810.pdf. Acesso em julho de 2006.

BULCÃO, Marly. O racionalismo da ciência contemporânea: Introdução ao Pensamento de Gaston Bachelard. Aparecida-SP: Idéias \& Letras, 2009.

CARNIATTO, Irene \& ARAGÃO, Rosália M. R. de. Investigação Narrativa: uma possibilidade para a pesquisa em Ensino segundo o Paradigma da Complexidade. Anais do IV ENPEC. Águas de Lindóia, São Paulo, 2003.

CONNELY, Michael F. \& CLANDININ, Jean D. Relatos de Experiências y Investigación Narrativa. In: LARROSA, Jorge. Déjame que te cuente: ensayos sobre narrativa y educación. Barcelona: Editorial Alestes, 1995, p. 11-59.

McEWAN, Hunter \& EGAN, Kieran. La narrativa em la Enseñanza, el aprendizaje y la investigación. Argentina: Amorrortur Editores, 1995.

MORIN, Edgar \& KERN, Anne Brigite. Terra Pátria. Porto Alegre: Editora Sulina, 2005.

PRIGOGINE, Ilya. O fim das certezas: tempo, caos e leis da natureza. São Paulo: UNESP, 1996.

CONTRERAS, J. D. La autonomia del Profesorado. Madrid: Morata, 1997 (há uma edição em português)

LÜDKE, Menga. A socialização profissional de professores - III etapa: As instituições formadoras. Rio de Janeiro: PUC-Rio, 1998b. Relatório de Pesquisa.

et al. Repercussões de tendências internacionais sobre a formação de nossos professores. In: Educação \& Sociedade, ano XX, n.68, dez. 1999.

NÓVOA, Antonio. Formação de professores e profissão docente. In: NÓVOA, Antonio (Org.) Os professores e sua formação. Lisboa: Dom Quixote, 1992a. 
O passado e o presente dos professores. In: NÓVOA, Antonio. (Org.) Profissão Professor.

Porto: Porto Editora, 1992b.

PERRENOUD, P. Práticas pedagógicas, profissão docente e formação. Lisboa: Dom Quixote, 1993.

SMEDLEY, L. Impediments to partnership: a literature review of school-university links. In: Teachers and teaching: Theory and Practice, 7 (2): 189-209, jun. 2001.

TARDIF, M. \& LÉVESQUE, M. Conclusion. In: AQUFOM. Enseignants de métier et formation iniciale; des changements dans les rapports de formation à l'enseignement. Paris/Bruxelas/Sherbrooke: AQUFOM/De Boek Université, 1998.

TARDIF, M. et al. Os professores face ao saber: esboço de uma problemática do saber docente. In: Teoria \& Educação. Porto Alegre, n. 4, 1991.

ZEICHNER, K. The practicum as occasion for learning to teach. In: Journal of Teaching Education, 14 (2): 11-27, 1987.

Novos caminhos para o practicum: uma perspective para os anos 90. In: NOVOA, A. (Org.) Os professores e sua formação. Lisboa: Dom Quixote, 1992.

Rethinking the practicum in the professional development school partnership. In: Journal of Teaching Education, 43 (4): 296-307, 1992b.

Campinas-SP - Início do Inverno Paulista Profa. Dra. Rosália Maria Ribeiro de Aragão rosalia.aragao@uol.com.br 